\title{
Exploration of the Promotion Scheme of Chinese Wushu for American Countries
}

\author{
Bing Duan ${ }^{1, a}$ Lijun Wang ${ }^{2, b^{*}}$ and Peng Chen ${ }^{2, c}$ \\ ${ }^{1}$ KangWon National University 24341, Korea. \\ ${ }^{2}$ Yancheng Teachers University 224002, China. \\ a87778133@qq.com, *, b wanglj432@126.com, c3224536341@qq.com
}

Keywords: Chinese Wushu; promotion scheme; modern information technology.

\begin{abstract}
Under the background of the growing prosperity of the Chinese Wushu culture abroad, it is obviously very important to understand the specific development condition of Chinese Wushu in a country. The Mexico is an important country in the America today, it is a multi-ethnic country, and it has important influence on other countries in America. In view of this, it is of great practical significance for the international development of Wushu to study the representation of Chinese traditional sports, the survival and development of Wushu in the Mexico. We carry out a comprehensive survey through the investigation method; specifically design promotion form, language communication, courses offering, specific contents as well as methods and approaches for promotion, the result shows that shortage of investment in the spread of Wushu needs to be attached importance to, moreover, the promotion of Wushu should be integrated with modern information technology. On the basis of the findings above, it can be concluded that the popularization system of Wushu can be combined with modern information technology, which goes hand in hand with the development of local economy.
\end{abstract}

\section{Introduction}

With the rise of the Chinese nation, the popularity and development of Wushu can be seen as an unprecedented boom. Especially in recent years, the development speed of Wushu is faster and faster. It has not only flourished in China, but also has become a new normal state in the world. In many countries in America, the number of people who learn Wushu is increasing year by year and it becomes a trend for Wushu to go to the world, which is one of the windows for world's understanding of China. But relative to the whole, Wushu is relatively slow in the economically backward America Mexico, and the Wushu population is far less than the developed countries such as Europe and Asia. However, it is worth affirming that American Mexico does not pay little attention to Wushu because of economic backwardness. On the contrary, they have a strong passion for Chinese culture and Chinese Wushu [1]. With the continuous improvement of China's status in the world's ethnic forest, the population of Mexico, who are eager to learn Chinese Wushu, is expanding rapidly. Mexico is an important member of America. Since the establishment of diplomatic relations with China in February 24, 1972, many Mexican leaders have visited Chinese leaders, making bilateral relations more and more intimate. Wushu has made great progress in the world and has been promoted by America as a branch line. Choosing Mexico as a pilot base for Wushu has not only a good foundation, but also a distinctive representation and radiation. It is one of the effective ways of promoting Chinese culture outwards with Wushu as the carrier.

In November 29, 2012, President Xi formally proposed the important thought of "The great rejuvenation of the Chinese nation". The revival work is ongoing continuously, and full of sound and color. Wushu, as one of the characteristics culture of Chinese nation, should bear the brunt. In addition, the revival and promotion are inseparable, so they should be carried out simultaneously and mutually promoting. Mexico as our "brothers", has honest and pleasant environment, and the local people are very friendly to Chinese, and worshiping Chinese Wushu [2]. But the local Wushu is out of order, and the senior national Wushu team level is only limited to Chinese National Wushu second or 
third levels, which does not have the high technology Wushu talents, and it is unable to highlight the essence of Wushu. Therefore, to promote Wushu in Mexico has broad prospects. The domestic Wushu talent are various and they should respond to national call to carry forward the national culture and make the project grow in size and strength, and truly do "point to guide the whole", so as to play good foundation for the development of Chinese Wushu in America.

In this study, the investigation is taken as the research method, to conduct a comprehensive survey of the effective dissemination of Wushu in Mexico, and on this basis, targeted design was carried out from promotion form, language communication, courses offering, specific contents as well as methods and ways for promotion. In the course of the promotion of Mexico, it can be found that the promotion of Wushu should be combined with the modern information technology, so as to achieve a better effect.

\section{Research Method}

The situation of the foreign communication of Chinese Wushu is analyzed in the case of the development of Wushu in Mexico. The main subjects are the leaders and coaches as well as students of the clubs, Wushu associations, local schools and Confucius institutes in Mexico.

According to different subjects (managers, educators and practitioners), we respectively design "Wushu development status questionnaire" with different contents, and the implementation of Wushu by managers as well as prospect planning of reform and Wushu development; arrangement and suggestions of the teaching status and teaching content by educators; and self-perception and interest of practitioners in the process of practicing Wushu [3]. The students investigated are mainly from the LORD BANDEN SHOOL, AMANI SHAO LIN GROUP, BEGEJA WHSHU CLUB, MBAGALATAI CLUB, MLANDIZI WUSHU CLUB, SHAO LIN WUSHU CLUB, Confucius College of Dodoma University, Dar Es Salaam University Confucius School, Mexico National Wushu team, and Cuba Island Confucian class, for being randomly selected. The questionnaire distribution statistics results are shown in table 1.

Table 1. Questionnaire distribution statistics

\begin{tabular}{ccccc}
\hline & Number of copies & Recoverable Number & Valid number & Valid rate \\
\hline Students & 260 & 253 & 215 & $85 \%$ \\
Coaches and leaders & 16 & 15 & 15 & $100 \%$ \\
\hline
\end{tabular}

Validity test: in order to ensure the validity of the questionnaire content, after the questionnaire design was complete, it was asked from the Wushu professor, and the questionnaire was revised several times. In the end, 10 professors and associate professors were asked to be examined by experts and scholars who have studied in the field of Wushu, for content validity test. The questionnaire validity test results statistics are shown in table 2 , and according to table 2 , the overall situation shows that the validity of the questionnaire is high and can be used.

Table 2. Questionnaire validity test results statistics

\begin{tabular}{cccc}
\hline Tittle & Valid & Basically Valid & Invalid \\
\hline Professors & 3 & 1 & 0 \\
Associate professors & 5 & 1 & 0 \\
\hline
\end{tabular}

Reliability test: in order to ensure the credibility of the questionnaire, this study used the retest method to make second questionnaires and tested the reliability of the questionnaire. 40 people were selected for pre-investigation. After two weeks, the same questionnaire was conducted on the same object for the second times, and they were tested two times before and after. The correlation coefficient between the two surveys was $\mathrm{R}=0.86, \mathrm{P}<0.01$ [4]. This showed that the reliability is significant, and the two investigations have high correlation, which is in line with the needs of this study. 


\section{Design of Promotion Scheme of Chinese Wushu to Mexico}

\subsection{Promotion Form}

The exchange of Chinese traditional culture in the international scope is the widely spread and promotion to the Chinese Wushu culture. It integrates the Chinese traditional Wushu, which embodies our traditional philosophy and classical aesthetics, displays rich connotation and provides good material for the construction of Wushu theory system. Because of the different perspectives, there are different ideas in the appearance of the problem, and the degree of the affection of the international friends to Wushu is also reflected in many aspects. The traditional sport idea of Wushu paying attention to the development of both virtue and talent is respected by those who learn Wushu. Especially for children, they pay more attention to the promotion of their self-constraint. The starting point is to teach the child to be a man and do things, not a simple obsessive love of Wushu. For Mexico Wushu practitioners, the education function of Wushu is relatively more prominent. While emphasizing moral education, it is an effective way to exercise and defend oneself. It also promotes the healthy propagation of Wushu culture abroad and promotes the role of good Wushu image. The Wushu culture spreading with Confucius school as the opportunity is the recognition of Chinese Wushu in the international scope. And through the spread of Wushu spirit, the fame of a state of ceremonies can be spread.

Employment market orientation: The popularity of Wushu is not only the effectiveness of technical characteristics or the aesthetic feature of Wushu, but also the good employment prospects attract young people to actively participate in it, so as to seek a decent job. Different Wushu organizations, in Mexico, set up a club for the Wushu technical movements teaching. However, how to achieve a good evaluation of the learning effect and level is the actual problem for coaches and practitioners [5]. Emergence of Wushu level system assessment form provides a new way to solve this problem. Because the existing Wushu club makes free training for coaches, and according to its own rules rank assessment methods combined with the level scoring evaluation system, standardized examination and systematic evaluation are conducted, so as to meet the students' ability and level. The basis and prerequisite for the completion of this process is that coaches need to systematically manage their instructors, so as to ensure the integrity and high quality of the implementation. If it meets the requirements, the instructor can recommend employment to the local security company to obtain decent work and obtain economic benefits.

Construction of the Wushu dissemination base under the official guidance: Mexico is currently preparing for the establishment of the Shaolin Wushu base and has won the recognition from leaders of Chinese embassy and Mexico sports department. The specific location plan is in the National Stadium of Mexico. The choice of the venue will parallel treat Wushu and other sports items, forming a resultant force with other sports events, and has played a good official publicity effect. According to the results of the survey, some high school students expect to establish a special school of full-time Wushu teaching and change the current Wushu teaching. Therefore, it is able to cooperate with local Chinese companies, to achieve the employment. In addition, it is hoped that the base can cultivate excellent students and send wages to students with excellent Wushu foundation. The monthly income is fixed, to encourage them to actively participate in Wushu practice as well as participating in performances. The base guides the students to carry out commercial performance to maintain the normal operation of the base, and students get good conditions to study.

The combination of tourism in different areas and Wushu competition: When promoting the growth of local tourism consumption, it is necessary to promote the understanding of Wushu culture. Combined with the characteristics of Wushu competition in domestic society, it is cooperated with the Mexicon local travel agency. The competitions are organized, and at the same time, it is suggested to travel locally. Culture and economy are widely spread throughout the world. While promoting the continuous development of Wushu culture in China, Wushu oriented tourism projects with local characteristics can become a new economic growth point and have a positive effect on local employment. 


\subsection{Language Communication}

Body language can express the unique cultural thought of Chinese Wushu. Since Wushu is derived from Chinese classical philosophy and aesthetic thought, the Wushu culture produced by the relatively abstract ideological system is also "intriguing". Due to the lack of understanding of our traditional culture, foreign practitioners are in the fuzzy state for the understanding of Wushu in the course of practice. The collision of the western thought and the traditional abstract thought, which is used to quantifying, has formed the ideological understanding that the language is difficult to be translated accurately. As a result, it is a long-term and arduous task to correctly translate the content of Wushu scientifically and rationally. At the present stage, the translation of Wushu in China is still in a wide range of languages, such as English. As a country in remote areas, Mexico is still waiting for insight to further scientifically and effectively translate traditional Wushu culture to expand the scope of Chinese Wushu cognition of "Wushu originated from China and belonged to the world" [6]. Wushu has been spreading abroad for hundreds of years, and Wushu has long been recognized as a business card of the Chinese people so that it has been recognized worldwide. Indeed, in the hearts of the people of Mexico, Wushu is also one of the excellent forms of Chinese culture. With the rapid expansion of Western "fast food culture" in the world, the diversity of forms of Wushu also need to be further strengthened. It is an important topic of Wushu to the broader space how to realize the diversified communication of Wushu limited to the performances.

The vast land of our country has bred a variety of cultural forms, influenced by different conditions, such as climate, national customs and so on, and Wushu culture has different forms. For the strategy implementation of Wushu going out, Chinese level system is undoubtedly an important step. The establishment of Chinese Wushu level system promotes the standardization of Wushu. And complex Wushu movements are simplified and classified, to meet different groups of practitioners [7]. The popularization of Wushu level system is a sort of Wushu technical movement and different styles boxing, which is beneficial for different groups to practice. In the external display process, it reflects the relatively uniform representation form, and facilitates the practice of foreign groups and understanding of Wushu culture.

Language, as the main obstacle in the course of teaching, is an important factor affecting the effective communication of Wushu. Because of the characteristics of local culture, the colonialist era has a deep influence on Mexico. It is inevitable to choose a language where both sides can communicate. Chinese as a difficult language to learn in the world, learning Chinese in Wushu teaching is not impossible, but the progress is slow that it makes it difficult to achieve the effect of effective communication. Wushu teaching process is fast and compact, so it is not realistic. It is more reasonable to use English as the official language to carry out teaching exchanges.

\subsection{Course Offering}

Because of the differences between Chinese and Western cultures, the integration and reference of culture cannot be achieved fast. The external output of Wushu culture also needs to be integrated with the different ethnic cultures of Mexico. Because of the differences between Chinese and western language, in the translation process of the China language for western language, although in the historical background of Chinese language, it still has the translator cultural color, which can better be understood by the translator's country or nation. "White crane spreads its wings" uses Chinese usual killing with kindness skills. Its graceful movement, like a white wing open and dances, with strong visual beauty and language beauty. Because of the differences between languages, when translation to the world, the meaning of language can be explained in terms of the meaning through the mother language of Wushu learners. The opening of the Wushu course not only has essential significance in the study of the technical movement, but also important in the dissemination of the cultural thought of Wushu. As a result, the "civil and military" communication type of Wushu, in the process of abroad spread, is an effective strategy.

Wushu spread uses diversified development ideas, to learn western open societies, schools, and clubs. The dissemination of Wushu with blood is liberated in the bondage of feudal ideology, but the rate of progress is slower than its development needs. Compared with the western competitive sports, the competitive sports participation rule of "everyone is equal and each one has equal opportunity" 
has been recognized by different groups in the world, and the realization of individual value is self-display in different groups. One of the advantages of Chinese Wushu is that the people of Mexico have a special liking for the beautiful feeling of Wushu. The richness of Wushu ideological connotation is incomparable with other projects. For instance, the harmony thought and self-improvement give the different feelings for foreign learners. The equal and free atmosphere of communication is popular among different social groups. This provides conditions for the development of different social organizations, such as cooperation and clubs.

Focusing on the importance of translation, from the perspective of different cultural forms, is an important guarantee for the opening of the curriculum. Although China and Mexico have obvious cultural differences, with the Chinese cultural exchanges with Mexico, and the translator constantly learn Mexico cultural background, it will make the people of Mexico better understand the Chinese traditional culture and some Wushu professional vocabularies. As Wang Yuechuan said, "Today's China should have their own innovation in the cultural development road. There are different views with the western culture that they cannot live under the shadow of the western culture." [8] From the perspective of Chinese and western culture cross-exchanges, Wushu culture communication and culture deposits provide the basis for translators at home and abroad to explore the international Wushu. For translators at home and abroad who cannot deeply understand Wushu professional vocabularies, they should understand the differences between Chinese and Western culture. And only in this way can they better interpret its meaning in the process of translation and preserve the basic meaning of Wushu culture. Therefore, the Chinese culture, in the process of international cultural communication, can establish a better image, to achieve the objective of China culture being gradually recognized.

\subsection{Specific Content}

Media sports - the realistic landscape of the international communication of Wushu. Cultural landscape is very significant in today's society, and culture is becoming more and more media-oriented. The Chinese Wushu culture has a profound and long history and it has been a good reputation in the world. But as the western sports culture, through the media, lets the world know their culture, and with their preconceptions, the Chinese sports culture has gradually fade out of the vision and the status has been greatly reduced, sometimes accompanied by the cultural crisis. Wushu started from China, and its development can't stagnate. "It needs not only our continuous exploration and innovation in learning, but also keeping pace with the trend of the times, and we need to use the power of the media to let Wushu culture go abroad and carry forward in the world." This is what Xu Cai, the former chairman of the Wushu association, said in his famous works "Xu Cai Wushu anthology". From this point of view, it is found that media has led the trend of Wushu culture and occupies a pivotal position in modern culture.

To absorb its essence -- let the culture exceeds the tradition. Wushu culture should keep itself in international communication and do not lose their individuality. Wushu Culture in Chinese culture is unique in the world, it shows the unique charm of traditional culture China and spreads in the form of sports. Of course, since traditional culture has its enduring charm, it should be regarded as the basis for cultural communication. Wushu culture should also regard traditional culture as a reference when it comes to external communication [9]. Wushu culture should not only maintain the unique characteristics of the culture, but also innovate the traditional content on the way to deal with the international development. We should keep pace with the times and adapt to the differences between Chinese culture and Western culture so that it can surpass itself. But the tradition of Wushu culture is not copying the original cultural content. It must synchronize with the times, to make it have some innovation and trade-offs to cater for the requirements of the times so that it can last for a long time.

Olympic events provide a broad platform for the development of competitive sports, and at the same time, it brings a great impact on different forms of traditional sports in the world. How to choose in traditional Olympic games is an important issue facing the development of Wushu at this stage. The same as fighting skills, but because of the different rules, in the "competition", Wushu often puts forward higher requirements for the establishment of referees and rules, and it is not easy to comply with the characteristics of the two movements. In order to promote the athletics feature of Wushu, all 
kinds of Wushu championships were held in Mexico to bring Wushu into the international fight stage, so as to get more attention. It is a good strategy for Wushu culture to spread abroad in the process of "going out" to achieve diversified development and adapt to the development needs of different regions.

\subsection{Methods and Approaches}

In Mexico visit and investigation, it is learned that the content of some club practice is somewhat similar with karate and Taekwondo movement. In the interview process, those who interviewed cannot clearly express, but they think it is a Wushu action. This phenomenon should arouse our attention and reflection. The awareness and understanding of Wushu for foreigners are unclear, the understanding of Wushu culture can be attributed to the misleading ideas of diverse connotation in the process of Wushu idea heritage, which will have adverse effects on the spreading of Wushu. If Wushu is merely a competition between sports and western sports, it will lose the traditional culture form of Wushu, but a Western tool with competition orientation and economic feature. Therefore, we have to take carrying forward the Chinese spirit as an important way to spread Wushu, and to make a wide spread through giving the ideological culture by technical action. In order to manifest the national spirit, the spread of Wushu in the world needs to transform from a single technology communication to a diversified spreading of spirit, thought and technology culture.

With the development of economic globalization, the influence of Wushu in the whole world is increasing. It, in an equal position, dialogues with other culture. To go into the world with cultural diversity is not to prove the status of Wushu in the world sports culture, but to emphasize its positive effects on human beings. Thus, it not only can regulate the body's health, but also regulate people's psychological activity and let the body and mind healthily developed. The wide spread of Wushu in the world is not only the transformation of technology propagation to cultural transmission, but also requires the progress of cultural soft power, such as the development and progress of the times and the society, and even the personal attention and recognition of Wushu [10]. There is no doubt that the advent of the era of globalization provides opportunities for the development of China and challenges the development of Wushu culture in the world.

During this period, China firmly grasped the opportunities, boldly faced challenges, and continuously expanded its economic and military capabilities, and its influence in the world has been continuously strengthened. At the same time, it also won the right to speak in the participation of international politics, economy and culture. It provided extensive development platform and diversified development channels for Wushu culture to spread widely in the world through literature, art and sports. The spread of Wushu in the world is not only between people or face-to-face oral teaching mode, but also displayed in the form of all flowers blooming together, which uses the Internet and real society two approaches. Today, Chinese reform is deepened and accelerated and cultural strategy is extensively developed. It is relatively easy for Chinese residents to go abroad, which provides the material basis (experts and scholars to give lectures, visits, technical immigrants, and a large increase in population) for the foreign exchange and cooperation between Wushu talents. Wushu promotion activities (film and television media, animation, stage performances and events in Kung Fu drama) and competitions with Wushu as the core are widely carried out. The above approaches have become the important channels for the spread of Wushu in Mexico and the world. And our communication with Mexico army, police force and all levels of staffs has also opened up a new medium for the spread of Wushu.

\section{Conclusion}

The effective dissemination of Wushu culture in foreign countries is the only way for the development of Wushu. The path to adapt to its development should be studied in depth according to the characteristics of different regions. Under the guidance of the International Wushu Federation, the spread of Chinese Wushu in Mexico has gradually changed from a single technology to a comprehensive communication form of more abundant Wushu thought and technology progress. The information age has brought a new opportunity to the development of the world culture, and the 
internationalization of Wushu has opened up a broad prospect. It is necessary to keep pace with the development concept of our country "Internet+", grasp the pulse of the development of Wushu culture in foreign countries, and form an effective force, so as to vigorously promote and apply information technology, and to comprehensively and pragmatically promote the internationalization of Wushu.

\section{Acknowledgments}

Fund projects: Jiangsu Province Social Science Fund Project (16TYC002).

\section{References}

[1] Kuteeva, M., \& Airey, J. (2014). Disciplinary differences in the use of English in higher education: Reflections on recent language policy developments. Higher Education, 67(5), 533-549.

[2] Yan, H., Wang, Q., Liu, L., Fang, Y., Dai, F., \& Chen, D., et al. (2015). On national culture transmission in college wushu education of jiangsu. Wushu Science.

[3] Ding, C., Zhang, N., \& Mei, H. (2017). "going global” strategy for Chinese culture development: taking confucius institute wushu performance tour as an example. Journal of Capital University of Physical Education \& Sports.

[4] Liang, X., \& Wang, P. (2015). On the value of ancient chinese literature elements in the dissemination of wushu in adolescents —— taking "wushu - new three character book" as an example. Wushu Science.

[5] Wu, W., \& Wshu, S. O. (2015). The influence of introducing rank system of wushu into teaching in primary and middle schools on the spread of wushu. Wushu Science.

[6] Wang, Y. (2016). The way and influence of wushu rank system of college wushu dissemination. Journal of Shangqiu Vocational \& Technical College.

[7] Tang, M. G., \& Cai, Z. L. (2016). Survival mirror and career change of wushu practitioner groups in the early stage of modern times. Journal of Beijing Sport University.

[8] Huang, L., Zhao, Y., Graduate School, \& University, W. S. (2015). The enlightenment of tv program "where is dad" for wushu dissemination_- the feasibility of "where is heroes". Wushu Science.

[9] Gao, X. M. (2016). Value orientation of mass communication of contemporary wushu culture from the perspective of cultural power strategy. Journal of Hebei Institute of Physical Education.

[10] Wen-Hui, M. A., Bei, L. I., Zhang, X. Q., Song, Y. Q., \& Ling-Yun, L. I. (2016). The spread of hebei wushu culture and the present situation and countermeasures of its industrial development-a case study of cangzhou wushu. Journal of Shijiazhuang University of Economics. 